\title{
Parents' Knowledge Attitude and Practice (KAP) About Retinopathy of Prematurity (ROP) in Bangladesh
}

\author{
Bimal Chandra Das ${ }^{1}$, ASM Wali Ullah², Muhammad Zahangir Alam ${ }^{3}$ \\ ${ }^{1-3}$ Abdul Malek Ukil Medical College, Noakhali, Bangladesh
}

\begin{abstract}
Purpose: To measure the Knowledge, Attitude and Practices of parents/caregivers about ROP in the rural setting of Bangladesh.
\end{abstract}

Study Design: Cross-sectional descriptive study.

Place and Duration of Study: Rural area of Bangladesh, from August 2019 to September 2019.

Methods: A total of 80 preterm babies' parents/caregivers were interviewed. Quantitative data and qualitative data were also collected through 6 Informal Group Discussions and 2 In-depth Interviews. There was a one-day session with all persons involved with the study for clear understanding of the study goal and every item of the format and interview schedule. The study format and interview schedule were given to one social scientist and one public health expert in determining content validity. Their comments were incorporated in finalizing the research instruments. The filled-in formats and interview schedules were edited immediately after the collection. Both quantitative and qualitative data were collected for the study.

Results: The most common risk factor for ROP was oxygen supply $(79 \%)$, Bio-safety $(67 \%)$ and weight $(66 \%)$. The major reasons for not screening for ROP were lack of awareness (84\%), lack of knowledge (48\%), family related issues (77\%), socio-economic condition (78\%), distance $(55 \%)$, frustration $(65 \%)$ and overconfidence (52\%). About $86.4 \%$ (Cl: 80.3 - 85.2) had faced difficulties to obtain ROP services. We found significant association between facing treatment difficulties and caregiver knowledge about ROP and time of age of screening for ROP $(p<.001)$.

Conclusion: The majority of parents/caregivers suggested for ROP screening, and put recommendations to improve mother anti-natal care (ANC) and strongly supported community awareness campaign to reduce the ROP related burden in rural setting.

Key Words: Retinopathy of Prematurity, Bangladesh, Attitude, Prematurity, Infant Mortality.

How to Cite this Article: Das BC, Wali Ullah ASM, Alam MZ. Parents/Caregivers' Knowledge Attitude and Practice (KAP) About Retinopathy of Prematurity (ROP) in Rural Setting of Bangladesh. Pak J Ophthalmol. 2020, 36 (2): 124-129.

Doi: $10.36351 /$ pjo.v36i2.992

Correspondence: Bimal Chandra Das

Abdul Malek Ukil Medical College, Noakhali, Bangladesh

Email:drbimalcmc28@gmail.com

Received: February 4, 2020

Accepted: March 15, 2020

\section{INTRODUCTION}

Neonatal Mortality Rate (NMR) in Bangladesh is 23 deaths per 1,000 live births and still there is a big gap in NMR between rural and urban areas. ${ }^{1,2}$ Main causes of neonatal deaths are prematurity $(29.7 \%)$, birth asphyxia (22.9\%) and sepsis $(20 \%){ }^{3}$ The above statistics show that the high rates of premature birth in 
the low and middle-income countries give rise to Retinopathy of Prematurity (ROP), which is becoming an epidemic.

Approximately 15 million babies are born each year globally and of these 3 million babies are born in Bangladesh and 400,000 (13.33\%) of these babies are born premature or with low birth weight and among them around $280,000(70 \%)$ babies are born in rural areas with significant risk of ROP. ${ }^{4,5}$ Evidence shows that the incidence of severe ROP in Bangladesh ranges from 11-21\% among babies born with low birth weight, whereas in developed countries the figure ranges from 5-8\%. ${ }^{6,7}$ The incidence of ROP varies from $38-52 \%$ among low birth-weight babies in India and it is estimated that approximately 500 children are getting blind each year in India due to ROP. ${ }^{8,9,10}$ In Bangladesh, the rate of low birth weight is high as well as the preterm birth. Evidence shows that neonatal mortality contributes between $40-70 \%$ of infant mortality and trends of neonatal mortality are declining less rapidly compared to infant and under 5 year mortality. ${ }^{11}$ For instance, the risk of a neonatal death due to complications of preterm birth is about twelve times higher for an African baby than for a European baby. ${ }^{12}$ Despite growing national and international attention focused on eye care services in recent years, the importance of ROP in newborn babies remains neglected in Bangladesh. Very recent data show that Rang Pur district has the highest rates (28\%) of Low Birth Weight (LBW) in Bangladesh. Lack of parents/caregivers' Knowledge, Attitude and Practice (KAP) and socio-economic factors may contribute to gaps in screening and treatment in rural setting in Bangladesh. KAP of parents about ROP do not lessen its importance as a subject of study as it is one of the major causes of poor uptake of ROP services and treatment.

In order to prevent and render services to those who need it there should be enough information to the decision makers who could be government, private and even voluntary agencies. Theoretically, this information is required for making any practical plan but unfortunately, they are almost absent in the country possibly for lack of interest in research and non-availability of funds for it. Therefore, the study aims to measure the KAP of parents/caregivers about ROP in the rural setting of Bangladesh. Secondary objectives were to find out the socio-economic characteristics of the parent/caregiver of ROP neonate and to determine the practices of parent/caregivers towards health seeking behavior.

\section{METHODS}

This was an observational and cross-sectional study. The study followed mixed method combining both quantitative and qualitative analysis. The quantitative methods included a survey of parent of the neonate while qualitative approach included formal group discussion and key informant interview. A pilot study was conducted to test the questionnaire before the main study. The study was conducted in the Rang Pur district (Southern part of Bangladesh), Bangladesh. A total of 80 preterm babies' parents and caregivers were interviewed. In addition to these, quantitative data and qualitative data were also collected through 6 informal Group Discussions (IGDs) and 2 in-depth interviews (IIs). Each IGD was attended by 5 to 7 participants. For conducting IGDs and in-depth interviews two separate interview guides were developed. There was a one-day session with all persons involved in the study for clear understanding of the study goal and every item of the format and interview schedule. The study format and interview schedule were given to one social scientist and one public health expert in determining content validity. Their comments were incorporated in finalizing the research instruments.

The questionnaire contained three domains, including knowledge (considering preterm babies health problems, sources of information about ROP, ROP related complications, knowledge about time of screening, place of ROP treatment, knowledge about ROP consequences), attitude (Lost interest after initial one or two visits, Gender bias, Lack of awareness of the serious nature of the disease, Fear of the procedure, Frustration with prolonged NICU admission, Over confidence (nothing will happen to my baby), and practice (Unsupportive family (no permission from home), sickness in the family (caregiver required) and regular checkup. Detailed questionnaire is given in table 1. The responses were scored by the correct answer. The SPSS statistical package was used for analyzing the data. Quantitative data were entered into the computer for analysis. Descriptive analysis (Central tendency, univariate, bivariate, multi-variate, Chi square test) was carried out. The level of significance used was at 0.05 . Reports on each IGD and in-depth interviews were prepared by the moderator using hand notes and recorded discussions. 
The verbatim was interpreted by the principal investigator and his associates. Data responses were coded thematically. The written reports were cut into pieces according to coded theme and then the same coded responses were placed together to be read and interpreted jointly by researchers. All qualitative data was analyzed manually.

Written and verbal consent was obtained from each participant after explaining the purpose and nature of the research. Participation in the study was on a voluntary basis and participants were informed of their right to quit/refuse their participation at any stage of the study if they did not want to participate. Moreover, confidentiality of the information was assured by using an anonymous consent form.

\section{RESULTS}

The study included both male and female respondents but the number of female respondents were 3 times $(77 \%)$ more than the male respondents (23\%). Average age of parent was $26.3( \pm 6.4)$ years. Average monthly income was BDT 20,490 $( \pm 3765)$. The literacy rate among the mothers of the neonate was as high as $53 \%$ as compared with father of the neonate $(47 \%)$. We found significant differences in education by gender $(p=0.02)$. The mothers under study were married at an average age of 19 years and the standard deviation being only 3.2 years affirms the early marriage of almost all women in the area. The first baby born to them was at the age of 20.3 years. This means within a period of less than 2 years of their marriage they became mothers. The mean distance of attendees' home from ROP treatment center (highest range 155 kilometers and lowest was 13 kilometers) was 37 kilometers. The majority of the respondents identified that common risk factor for ROP was an oxygen supply (79\%), Bio-safety $(67 \%)$ and weight $(66 \%)$. The major reasons for not screening for ROP were lack of awareness (84\%), lack of knowledge $(48 \%)$, family related issues $(77 \%)$, socio-economic condition $(78 \%)$, distance $(55 \%)$, frustration $(65 \%)$ and over confidence $(52 \%)$. We asked respondents about ROP risk factors, knowledge about ROP disease, treatment places and sought their attitude and practices on ROP and we found that there was strong association between parents/caregivers, knowledge attitude and practice and ROP of their babies (Table 1).

Respondents were asked whether they experienced difficulties obtaining ROP services for their babies. About $86.4 \%$ (CI: $80.3-85.2$ ) of respondents said they had experienced difficulties; 45\% (CI: 18.7 $23.4,72.5-80.8$ ) said they did not know where or when to take their child for ROP treatment; $61 \%$ (CI: 14.1-12.6, 55.1 - 63.2) said the ROP treatment location was too far away; and $66 \%$ (CI: $52.3-65.8$ ) said they experienced long wait times at facilities. There were significant differences in facing treatment difficulties and caregiver knowledge about ROP risk factors and time of age of screening for ROP (CI: $38.7-45.6,51.6-53.5, \mathrm{x} 2=9.80$, df $=9$, Cramer's V $=0.25 \mathrm{p}=0.001)$. The vast majority $(86 \%)$ parents/caregivers (CI: $79.3-83.2)$ agreed that ROP screening could affect babies' eye health, whilst 89\% (CI: 81.4 - 86.4) agreed that mother ANC and knowledge about time of age of screening could help in protecting from ROP related diseases. Majority (92\%) of caregivers (CI: 87.4 - 93.5) supported community awareness campaign as an effective tool to protect babies from ROP related diseases. Recommendations were sought from the parents/ caregivers and they suggested that community campaign was needed urgently because most of the guardians were not aware of the disease, its risk factors, timing of screening or treatment and its consequences. Majority of the participants agreed that strengthening referral network, following the coordination strategy and identifying the cause of missing follow up was urgently needed. The guardians also highlighted that causal point should be rationalized like the use of $\mathrm{O} 2$, blood transfusion and use of ventilators. Finally, guardians said that people should be made aware of the ROP through televisions, posters, and billboards.

\section{DISCUSSION}

Parents/caregivers Knowledge, Attitude and Practices (KAP) are very important issues of early identification and ensure proper treatment of babies with Retinopathy of Prematurity (ROP). Parents KAP and standard level of ANC is necessary to improve the quality of life of ROP babies. Neonatal mortality and morbidity has declined remarkably in Bangladesh and has achieved the Millennium Development Goals. Even then, ROP still is an alarming issue in rural areas of Bangladesh. The KAP of parents/caregivers and standard screening protocol for ROP is a very effective tool for the preterm babies. ${ }^{13,14}$ 
Table 1: Level of Knowledge, Attitude and Practice of parents/caregivers about ROP.

\begin{tabular}{|c|c|c|c|c|c|}
\hline Knowledge, Attitude \& Practice & $\begin{array}{l}\text { Yes } \\
(\%)\end{array}$ & $\begin{array}{l}\text { No } \\
(\%)\end{array}$ & $95 \% \mathrm{CI}$ & $\mathbf{x} 2$ & $\begin{array}{c}\mathbf{P} \\
\text { Value }\end{array}$ \\
\hline \multicolumn{6}{|l|}{ Knowledge } \\
\hline Heard about ROP & 52 & 48 & {$[61.9-72.5,18.2-23.6]$} & {$[15.80,6.80]$} & .005 \\
\hline Heard about ROP related complications & 38 & 62 & {$[31.3-36.9,59.2-66.5]$} & {$[7.60,13.70]$} & .04 \\
\hline Knows about ROP Risk factors & 42 & 58 & {$[31.3-35.8,58.2-65.8]$} & {$[6.90,12.80]$} & .003 \\
\hline Knowledge about time of screening & 43 & 57 & {$[38.7-45.6,51.6-53.5]$} & {$[9.80,10.60]$} & .001 \\
\hline Know the place of ROP treatment & 55 & 45 & {$[18.7-23.4,72.5-80.8]$} & {$[6.90,14.70]$} & .05 \\
\hline Knowledge about ROP baby health consequences & 32 & 68 & {$[19.9-24.6,71.5-77.4]$} & {$[5.50,13.85]$} & .05 \\
\hline Knowledge about ROP \& Eye Health & 23 & 77 & {$[20.7-24.9,69.9-76.7]$} & {$[6.75,16.97]$} & .002 \\
\hline \multicolumn{6}{|l|}{ Attitude } \\
\hline Lost interest after initial visits & 48 & 52 & {$[69.9-75.5,25.0-29.8]$} & {$[19.67,6.60]$} & .50 \\
\hline Gender bias & 64 & 36 & {$[59.8-63.4,29.6-35.2]$} & {$[11.76,8.97]$} & .60 \\
\hline Awareness about seriousness of disease & 65 & 35 & {$[80.3-85.2,10.7-13.8]$} & {$[17.80,6.78]$} & .02 \\
\hline Fear of the procedure & 34 & 76 & {$[88.9-94.4,4.4-6.9]$} & {$[19.85,4.50]$} & .04 \\
\hline Frustration with prolonged NICU admission & 77 & 23 & {$[71.8-76.0,18.4-22.5]$} & {$[15.90,9.35]$} & .05 \\
\hline Overconfidence (nothing will happen to my baby) & 52 & 08 & {$[87.4-93.5,4.4-7.8]$} & {$[18.78,5.50]$} & .03 \\
\hline \multicolumn{6}{|l|}{ Practice } \\
\hline Unsupportive family & 35 & 77 & {$[26.4-31.6,69.8-75.7]$} & {$[7.84,15,65]$} & .50 \\
\hline Sickness in the family (caregiver required) & 69 & 31 & {$[81.9-85.5,8.5-11.0]$} & {$[19.56,5.50]$} & .05 \\
\hline Regular checkup & 45 & 55 & {$[67.6-75.5,9.3-100]$} & {$[17.22,6.90]$} & .002 \\
\hline Believe that premature babies do not need screening & 21 & 79 & {$[0.5-2.20,92.0-97.5]$} & {$[23.77,2.60]$} & .002 \\
\hline Baby too sick to travel for screening & 29 & 71 & {$[26.8-29.3,66.3-70.4]$} & {$[6.90,12.77]$} & .50 \\
\hline Other babies did not have a problem, mine too will not & 44 & 56 & {$[22.8-27.3,64.3-75.4]$} & {$[5.70,11.76]$} & .05 \\
\hline
\end{tabular}

We found that majority of the parents/caregivers have poor knowledge $(41 \%)$, attitude $(55 \%)$ and practice $(40 \%)$. The same studies were conducted in India and Nigeria and found nearly same results. ${ }^{15,16}$ This may be as a result of poor awareness program at community level or rural areas and about $92 \%$ suggested for awareness campaign among parents/ caregivers as well as community level to improve ROP KAP. The alarming issue is that poor knowledge, low rate of ROP screening and guardian's frustration may have negative effect on baby's quality of life. Rang Pur is the district where highest number of preterm babies are born and we need special community awareness program to improve the situation. The knowledge and practice among our population is poor in comparison with previous studies. ${ }^{17}$ There is statistically significant association in the responses concerning knowledge of screening ROP of babies between parents/caregivers and risk factors of ROP (P $>0.001)$. This suggests that increase of knowledge of parents/caregiver will improve the uptake of ROP services. This has implications in the readiness by parents/caregivers to address the challenges of ROP but it will improve the situation immediately. The emerging epidemic of ROP blindness in rural areas in Bangladesh as a result of large number of preterm babies and high oxygen is considered the most important risk factor for ROP with $\mathrm{LBW}$ being the greatest predictor of severity. ${ }^{18}$ Our findings reveal that KAP and socio-economic conditions are significant and independent factors for ROP. However, reports have found ROP in cases without oxygen therapy and even after oxygen therapy, not all premature infants develop ROP. ROP is a multifactorial disease involving many factors. Lowgestational age, low-birth weight, sepsis, oxygen therapy, respiratory distress syndrome and blood transfusion have been suspected to influence the development of ROP. ${ }^{19}$ We found a significant relationship between parents/caregivers knowledge and attitude about ROP and risk factors of ROP. This shows that even though most parents/caregivers did not know the accurate factors related to ROP, the attitudes of the respondents in this study were generally positive compared to knowledge and practices. Finally, Poor Knowledge, Attitude and Practice (KAP) on ROP, poor socio-economic conditions, distance barriers and lack of awareness programs are responsible for poor uptake of ROP services. $^{20}$

Mass media awareness and campaign program should be launched to create awareness among service providers, parents and care givers about the disease, its consequences and urgency of the treatment and 
follow-up. Before leaving the hospital, parents or caregivers of neonates should receive adequate counseling from the NICU service providers on the importance of ROP screening, treatment and ultimate consequences. All neonates who are at risk at NICU or who were at risk, but discharged earlier should be followed up appropriately for prevention of development of ROP.

The key limitation of the study was that due to time and resource constraints, we could not take representative samples from Parents/caregivers.

\section{CONCLUSION}

In general, parents/caregivers had poor knowledge, attitude and practice about ROP and the majority of respondents diagnosis have enough awareness of the importance of ROP screening and treatment. Although timely retinal screening of high-risk preterm infants a important to prevent the development of advanced ROP.

\section{ACKNOWLEDGEMENT}

Our appreciation to all the parents of the newborn for their patience and compliance.

\section{Ethical Approval}

The study was approved by the Institutional review board/Ethical review board.

\section{Conflict of Interest}

Authors declared no conflict of interest

\section{REFERENCES}

1. Chowdhury AH. Determinants of Under-5 mortality in Bangladesh. Open Journal of Statistics, 2013; 3: 213219.

2. Abir T, Agho KE, Page AN, Milton AH, Dibley MJ. Risk factors for under-5 mortality: evidence from Bangladesh Demographic and Health Survey. BMJ. 2015; 5 (8): e006722.

3. Cha S. The impact of the worldwide millennium development goals campaign on maternal and underfive child mortality reduction: 'where did the worldwide campaign work most effectively? Global Health Action, 10 (1): 1267961.
4. Blencowe H, Cousens S, Oestergaard MZ, Chou D, Moller AB, Narwal R, et al. National, regional, and worldwide estimates of preterm birth rates in the year 2010 with time trends since 1990 for selected countries: a systematic analysis and implications. Lancet, 2012; 79: $2162-2172$.

5. United Nations, Department of Economic and Social Affairs, Population Division (2015). World Population Prospects 2015 - Data Booklet (ST/ESA/ SER.A/377).

6. Akhter S, Hossain MM, Shirin M, Khalil I, Anwar KS. Blood Transfusion: A Risk Factor in Retinopathy of Prematurity. Bangladesh J Child Health, 2010; 34 (2): $38-43$.

7. Liton CS, Mahbubul H, Dipak KN, Azad CM. Screening for Retinopathy of Prematurity in Neonatal Unit - An Experience of a Tertiary Care Hospital in Bangladesh. Acad J Ped Neonatol. 2017; 3 (3): 555612. DOI:10.19080/AJPN.2017.03.555612.

8. Gergely K, Gerinec A. Retinopathy of prematurityepidemics, incidence, prevalence, blindness. Bratislavskelekarskelisty. 2010; 111 (9): 514-517.

9. Gopal L, Sharma T, Ramchandran S, Shanmugasundaram R, Asha V. Retinopathy of prematurity. A study. Indian J Ophthalmol. 1995; 43: 50-61.

10. Charan R, Dogra MR, Gupta A, Narang A. The incidence of retinopathy of prematurity in a neonatal care unit. Indian J Ophthalmol. 1995; 43: 123-126.

11. Shah PK, Navendran V, Saravanan VR, Raghuram A, Chattopadhyay A, Kashyap M, et al. Fulminant retinopathy of prematurity - clinical characteristics and laser outcome. Ind J Ophthalmol. 2005; 53: 261-265.

12. Lawn JE, Cousens S, Zupan J. 4 million neonatal deaths: When? Where? Why? Lancet. 2005; 365: 891900 .

13. Marchant T, Willey B, Katz J, Clarke S, Kariuki S, Kuile Ft, et al. Neonatal Mortality Risk Associated with Preterm Birth in East Africa, Adjusted by Weight for Gestational Age: Individual Participant Level MetaAnalysis. PLoS Med. 2012; 9 (8): e1001292. https://doi.org/10.1371/journal.pmed.1001292

14. Rotimi-Samuel A, Fajolu IB, Aribaba OT, Alimi H, Akinsola FB, Onakoya OA. Retinopathy of prematurity: A case report and challenges of management in Nigeria. Nig J Ophthalmol. 2013; 21: 27-29.

15. Jalali S, Hussain A, Matalia $J$, Anand $\mathbf{R}$. Modification of screening criteria for India and other middle-income group countries. Am J Ophthalmol. 2006; 141: 966-968.

16. Ayotunde T, Marry O, Melvin AO, Faniyi FF. Maternal age at birth and under-5 mortality in Nigeria. East African Journal of Public Health, 2009; 6 (1): 1114. 
17. Cha S, Cho Y. Changes in under-5 mortality rate and major childhood diseases: A country-level analysis. Asia-Pacific Journal of Public Health, 2016; 28 (2): 178-196.

18. Karna P, Muttineni J, Angell L, Karmaus W. Retinopathy of prematurity and risk factors: A prospective cohort study. BMC Pediatr. 2005; 5: 18.

19. Fortes JB, Barros CK, Lermann VL. Prevention of blindness due to retinopathy of prematurity at hospital de clinicas de portoalegre, Brazil: Incidence, risk factors, laser treatment and outcomes from 2002 to 2006. Actamedica Lituanica. 2006; 13: 130-6.

20. Grepin KA, Bharadwaj P. Maternal Education and Child Mortality in Zimbabwe. Elsevier. 2015; 44: 95117 .

\section{Authors' Designation and Contribution}

Bimal Chandra Das; Associate Professor: Concept and design, acquisition of data, analysis and interpretation of data and drafting of the manuscript.

ASM Wali Ullah; Assistant Professor: Acquisition of data, analysis and interpretation of data and drafting of the manuscript. Critical revision of the manuscript.

Muhammad Zahangir Alam; Assistant Professor: Analysis and interpretation of data and drafting of the manuscript and critical revision of the manuscript. 